\title{
Making the case for operating "Green": impact of environmental proactivity on multiple performance outcomes of Malaysian firms
}

\begin{abstract}
In spite of the significant amount of work that has been conducted to investigate the impact of environmental proactivity on firm financial performance, limited research has focused on other firm performance outcomes such as operational performance and stakeholder satisfaction. The roles played by interacting and mediating constructs have not been addressed adequately in the environmental proactivity/firm performance literature. Drawing on stakeholder theory and the resource-based view of the firm, this study on 291 firms in Malaysia has hypothesized that environmental proactivity is positively related to (1) operational performance, (2) organizational learning, (3) environmental performance, (4) stakeholder satisfaction and (5) financial performance. The study has also hypothesized that the types of technologies deployed to address environmental issues moderates the relationship between environmental proactivity and operational performance, whilst environmental performance mediates the relationship between environmental proactivity and stakeholder satisfaction, which in turn mediates the relationship between environmental proactivity and financial performance. Using structural equation modeling (SEM) for the data analysis, findings indicate that environmental proactivity is positively related to operational performance, organizational learning, environmental performance, stakeholder satisfaction and financial performance. Significantly, the mediating role of stakeholder satisfaction is also supported by the data even though the mediating role of environmental performance and the moderating role of types of technologies are not supported by findings.
\end{abstract}

Keyword: Environmental proactivity; Environmental performance; Operational performance; Stakeholder satisfaction; Financial performance; Malaysia 